\title{
Pandemia e biografia no jornalismo: uma análise dos relatos pessoais da experiência com a Influenza H1N1 em O Dia
}

\section{Pandemic and biography in journalism: an analysis of the personal accounts of experience with Influenza H1N1 in O Dia}

\author{
Igor Sacramento \\ Bolsista de pós-doutorado da Escola de Comunicação da UFRJ, onde atua como professor de cursos de graduação e de pós- \\ graduação. \\ <igorsacramento@gmail.com>
}

\section{Kátia Lerner}

Doutora em Sociologia e Antropologia pela UFRJ e doutora em Sociologia pela Universidade da Califórnia, nos Estados Unidos. Pesquisadora do Laboratório de Comunicação e Saúde do Instituto de Comunicação e Informação Científica e Tecnológica em Saúde (Laces/lcict). Membro permanente do corpo docente do Programa de Pós-Graduação em Informação e Comunicação em Saúde (PPGICS).

<klerner@icict.fiocruz.br >

\section{RESUMO}

Este artigo analisa os relatos pessoais da experiência com a Influenza H1N1 publicados em O Dia entre maio e agosto de 2009. Sob dois formatos distintos Viva Voz e Carta Aberta -, tais relatos se constituíram como uma forma de alargamento do discurso direto e da presença do "outro" dentro das reportagens sobre o assunto, ganhando um espaço específico e destacado para pequenas narrativas autobiográficas ("autobiografemas") ancoradas na experiência com a então nova doença. Nesses espaços autobiográficos, identificamos uma oscilação entre a vitimização, a vergonha, a culpa e a indignação. Concluímos que essa maior abertura à subjetividade e à alteridade garantiram reforços do pacto de referencialidade e da autoridade, próprios à enunciação jornalística.

Palavras-chave: Jornalismo. Autobiografia. Influenza H1N1.

\begin{abstract}
This paper analyzes the personal narratives of experience with $\mathrm{H} 1 \mathrm{~N} 1$ influenza published in the newspaper O Dia between May and August 2009 under two different formats: Viva Voz and Carta Aberta. This types of discourse constitutes an extension of direct speech and the presence of the "other" within the news reports, gaining a specific space to small autobiographical narratives ("autobiografemas") anchored on the experience with the new disease. We identified an oscillation between victimization, shame, guilt and indignation in these autobiographical spaces. We conclude that these autobiographical narratives reinforce the referential pact and authority of the journalistic utterance itself, because the subjectivity and the individual experience are important values of authenticity on contemporary societies.
\end{abstract}

Keywords: Journalism. Autobiography. Influenza H1N1.

\section{INTRODUÇÃO}

Em 24 de abril de 2009, a Organização Mundial de Saúde (OMS) anunciou o surgimento de um novo tipo de gripe, causado por um vírus pouco conhecido, sem formas de proteção definidas, sobre o qual se suspeitava haver um grau de letalidade maior do que o apresentado pelas modalidades conhecidas de 
Influenza. Este anúncio despertou um grande interesse midiático, o que foi constatado pela profusão de textos jornalísticos veiculados na época. Nos primeiros meses após o anúncio da OMS, identificamos que foi publicada uma média de 7 textos por dia sobre Influenza H1N1 nos três jornais monitorados (O Globo, O Dia e Folha de São Paulo). Esta intensa presença do tema na mídia perdurou até a chegada do inverno, quando se iniciou a progressiva diminuição do interesse sobre o que naquela época foi designado de "gripe suína".

$\mathrm{O}$ presente trabalho tem como objetivo analisar os textos publicados sobre Influenza $\mathrm{H} 1 \mathrm{~N} 1$, enfocando especificamente aqueles que apresentaram narrativas de cunho autobiográfico. Nosso intuito é identificar como esses relatos foram jornalisticamente apropriados e reorquestrados dentro de uma enunciação jornalística sobre a Influenza H1N1. Como foram produzidos, no jornal, espaços autobiográficos para relatos sobre a infecção ou a sua suspeita? Quais foram os modos autobiográficos de abordar a doença? Que estilos narrativos foram acionados? Que modos de enunciação foram propostos? Como esses relatos se relacionaram aos referentes "exterior"/"interior"? Como eles nos auxiliam a pensar sobre a doença e sobre o jornalismo em particular?

Para realizar tal proposta, tomamos como objeto empírico de análise o jornal O Dia. Até o final dos anos 1980, este periódico era considerado um jornal "popular", com forte ênfase nas matérias policiais, ampla presença de fotos impactantes e linguagem coloquial. Com sua aquisição por Ary Carvalho e a reforma implementada a partir de 1987, o jornal buscou um estilo intermediário, não chegando a ser um "jornal de referência", mas tampouco permanecendo um "jornal popular" (Coeli, 2003). Atualmente, seus leitores situam-se entre as camadas médias e populares do Rio de Janeiro. A despeito das mudanças assinaladas, ele, no entanto, guardou certas marcas de endereçamento a um público mais popular, menos elitizado, o que se expressa através de uma diagramação repleta de textos curtos, de uma diversidade de seções e de fotografias e imagens coloridas que ocupam considerável espaço, chegando às vezes a $50 \%$ da página. Serão duas destas seções, intituladas Viva Voz e Carta Aberta, os objetos de estudo deste trabalho.

Orecorte de análise se inicia em maio de 2009, pouco depois do surgimento da doença e quando esta efetivamente se configurou como pandemia, indo até o mês de agosto do mesmo ano, por ocasião do declínio do número de infectados. 


\section{SUBJETIVIDADE, AUTOBIOGRAFIA E REFERENCIALIDADE NA ENUNCIAÇÃO JORNALÍSTICA}

Em seu clássico artigo “Uma categoria do espírito: A noção de pessoa, a noção do 'eu'", Marcel Mauss evidencia como, a despeito de haver em todas as formas de sociedades existentes a presença de um sujeito empírico consciente de sua corporalidade e de sua individualidade espiritual, há diferentes formas de se conceber a subjetividade. Em outras palavras, ele chama a atenção à ideia de que a noção de sujeito é socialmente construída, e portanto trata-se de uma categoria "não-natural", que está em permanente elaboração, e varia conforme as visões de mundo presentes em cada sociedade. Para defender seu argumento, o autor acompanha a trajetória desta noção, que se expressou de diferentes modos, até chegar na concepção moderna na qual vigora a ideia de indivíduo enquanto "valor", ou seja, ser psicológico e unidade social relevante e ativa numa formação social, tomado como centro e foco do universo social (Mauss, 1974).

Neste tipo de sociedade, os valores da igualdade e liberdade são preponderantes, enquanto nas sociedades tradicionais, onde o valor se encontra na sociedade como um todo, tem-se uma organização holista, no qual os princípios de ordem e hierarquia preponderam (Dumont, 1985; 1992). Cabe ressaltar que a hegemonia de um determinado sistema de pensamento (seja ele individualista ou holista) nunca extingue a presença do outro, mas apenas o desloca a certos setores e configurações, cabendo somente verificar onde eles se estruturam.

É neste contexto que podemos localizar o surgimento das narrativas biográficas; na medida em que observamos a preponderância do indivíduo como valor é possível entender a crescente importância dada à narração de histórias que o tomam como eixo central (Velho, 1994).

A autobiografia seria uma das modalidades do biográfico e, embora a ele esteja associada, possui contornos próprios. Ao falarmos sobre autobiografia seria importante definir o que caraceriza e define este relato de si. Philippe Lejeune é um dos autores que mais se detacaram na discussão sobre o tema e sua breve definição do conceito representa um excelente ponto de partida. $O$ autor afirma que se trata de um "relato retrospectivo em prosa que uma pessoa real faz de sua própria existência, pondo ênfase em sua vida individual e, em particular, na história de sua personalidade" (Lejeune, 1994, p.50).

O "eu" autobiográfico conta com uma dupla função: de mediação entre o íntimo e o público e de referencialidade, calcada na experiência pessoal dos 
fatos e, portanto, na narração dos próprios sentimentos: naquilo que só o "eu" pode tornar público e dizer que é verdade. Toda representação de si adquire mais confiança do público na medida em que ela se baseia em procedimentos que se definem como parte do que Lejeune denomina de pacto autobiográfico (Lejeune, 2008). Ele é determinado por um compromisso duplo do autor com o leitor: por um lado, diz respeito a um "pacto de referencialidade" (a história narrada corresponde a algo que realmente aconteceu e, portanto, tem uma prova externa ao enunciado) e, por outro, constitui um "princípio de identidade" (o "eu" do enunciado é o mesmo que assina o relato e que se responsabiliza pelo que narra, ou seja, autor empírico, narrador e personagem principal são equivalentes). $\mathrm{O}$ "eu" agrega a identificação do autor como narrador e como protagonista. Sendo assim, o nome próprio é o lugar de articulação entre o que está dentro e o que está fora do texto.

Segundo Lejeune (2008), essa coincidência entre autor, narrador e personagem principal garantiria, por si mesmo, o "pacto autobiográfico": a confiança na narrativa porque ela é narrada por quem a viveu e a assinou. Ainda que realmente não haja uma coincidência de fato, há a produção de uma semelhança entre o sujeito da enunciação, do enunciado e o autor empírico. Sendo assim, a noção de pacto corresponderia a uma concepção de autor como o "dono da significação", com uma autoridade praticamente inquestionável sobre o sentido produzido nos seus textos, dos quais seria a fonte única e exclusiva. No caso da autobiografia, essa autoridade seria conferida pela produção discursiva do encontro da experiência narrada com a experiência vivida numa mesma pessoa. Assim, somente o indivíduo teria a autorização para narrar sua própria vida. Seria somente dele a narração autêntica. A vigência dessa condição colocou o texto numa relação de contiguidade com a "vida interior" do seu autor. O relato é mais do que reflexo de algo: é a extensão, o prolongamento, da "vida interior" no mundo exterior. Essa seria a raridade da produção autobiográfica: a capacidade singular de se expandir para o mundo mantendo-se o mesmo, "senhor de si" e de seu próprio discurso.

O que se quer destacar ao trazer as considerações de Lejeune é que, tradicionalmente, a enunciação autobiográfica estrutura grande parte do seu dizer numa referencialidade interior, baseada no "eu". Essa observação é especialmente pertinente, pois, ao confrontarmos com a enunciação jornalística, percebemos que esta é estruturada a partir de uma outra lógica, voltada para relatar a "realidade exterior", mas de modo a fazer com que o dito seja a simulação da presença do fato em si (Fausto Neto, 1991). 
Como já vimos, a enunciação autobiográfica investe no destaque do sujeito da enunciação e na sua proximidade com o autor empírico, justamente para conquistar o reconhecimento e o status de verdadeira, honesta e sincera. Ao contrário disso, a enunciação jornalística conta, tradicionalmente, com estratégias discursivas para "apagar" ou escamotear o sujeito da enunciação, de modo a valorizar o logos jornalístico, o conhecimento para tornar a palavra transparente em relação à realidade representada. Para tanto, ela tem sido regulada por macrocódigos (a língua, as matrizes culturais, as regras sociais, a ética, a deontologia profissional) e por microcódigos (os instrumentos enunciativos que são criados, internamente, por cada veículo, formalizados nos manuais de redação, mas ressignificados e reordenados pela rotina profissional). Dessa forma, a enunciação jornalística se estabelece como uma estrutura vazia, cujos procedimentos e configuração resultam mais do investimento que se faz nos códigos, técnicas, saberes e regras do que na produção subjetiva como uma criação relativamente autônoma e fundamentalmente pessoal (Fausto Neto, 1991), ou seja, fazendo com que a técnica domestique a subjetividade.

Um desses instrumentos enunciativos é a relação com o "outro". "Dar voz ao outro" tornou-se uma prática constituinte do jornalismo moderno, na busca pela isenção, neutralidade e pluralismo. As formas de aparição do outro nos enunciados jornalísticos se mostram mais explicitamente nas citações (ou nas sonoras, nas formas audiovisuais): no discurso indireto e no discurso direto. No caso do discurso direto, evidencia-se a demarcação de um espaço para a apresentação da fala do "outro". Ou seja, configura-se como uma maneira de trazer à presença o "outro", uma referência externa ao dito, mas que se interioriza nele.

O discurso direto no jornalismo (tanto nas formas de entrevista ou de citação) se ancora na palavra dita sobre a realidade como um "retrato fiel", na medida em que é atestada pelo nome, pela voz, pela imagem, pelo "outro" (Arfuch, 2010). Mas não se trata de um outro qualquer, mas de um "outro" legitimado. Trata-se, geralmente, daquele que se destacou em falar sobre o que sabe (o especialista), daquele que pode falar sobre aquilo que vivenciou na sua própria carne um fato marcante (a vítima) ou daquele que o viu acontecer com seus próprios olhos (a testemunha).

$\mathrm{Na}$ contemporaneidade, a concepção moderna de autobiografia (como uma forma de relato completo do "eu" sobre a sua vida) está reconfigurada. Passou a ser mais associada à preeminência do vivencial. Nesse sentido, o relato autobiográfico passou a aferir aos discursos o efeito de "vida real" - de "verdadeiramente ocorrido". Desse modo, poderíamos considerar a 
intersubjetividade gerada pelas formas biográficas também como um acordo, uma sintonia, produzidos pela enunciação autobiográfica, entre o autor e o leitor (Arfuch, 2010). Nesse momento, portanto, se verifica uma enorme expansão do espaço autobiográfico: uma arquitetura de textos, ficcionais ou não, que remontam a uma certa imagem do autor, contendo uma forma mais indireta de pacto autobiográfico. Não se trata de um texto no gênero autobiográfico, com todas as suas especificidades, como uma totalidade (início, meio e fim), mas com traços autobiográficos (Lejeune, 2008). Ou seja, o espaço autobiográfico é um "sistema de gêneros", uma confluência de múltiplas formas, gêneros e horizontes de expectativas.

Cabe a seguir investigar como essas questões se colocaram nos jornais. Como as narrativas de si aparecem nos jornais na cobertura de H1N1? Como são incorporadas dentro da enunciação jornalística? Como essas lógicas aparentemente opostas se relacionam e que efeitos de sentido imprimem aos eventos relatados, bem como aos personagens?

\section{A INFLUENZA H1N1 E OS ESPAÇOS AUTOBIOGRÁFICOS NO JORNAL O DIA}

O anúncio da OMS sobre o surgimento da Influenza H1N1 no México e no mundo provocou uma proliferação de textos jornalísticos sobre o tema. Observase que essas publicações em alguma medida se relacionavam à cronologia dos eventos epidemiológicos e àquilo que, na perspectiva jornalística, apresentava maior noticiabilidade. Para se compreender melhor a questão biográfica na cobertura da Influenza H1N1, caberia trazer uma breve visão panorâmica dos textos publicados e seu teor.

No mês de maio de 2009 , foram publicados no jornal O Dia 48 textos ${ }^{1}$ sobre a nova gripe. Nesse momento o tema predominante era a disseminação da doença pelo mundo e a possibilidade de sua chegada ao país, com o controle dos "casos suspeitos" e "monitorados". Ainda neste período falou-se muito sobre o primeiro caso confirmado no Brasil e a primeira contaminação autóctone (realizada em território nacional). Observa-se, em junho, um pequeno refluxo de publicações, com 38 textos, e nesse momento o grande debate girou em torno das medidas preventivas a serem tomadas (como o fechamento ou não das escolas e o adiantamento das férias). Ao final do mês ocorreu o primeiro óbito, canalizando o interesse da cobertura para o tema. Certamente não é

1 Por este termo estamos designando a produção textual realizada em diferentes formatos, tantos os opinativos quanto os informativos, nas suas variações internas. 
coincidência o expressivo aumento de publicações nos meses seguintes (77 e 84 em julho e agosto, respectivamente), quando a questão abordada permaneceu focada nos óbitos, mas já particularizada no que posteriormente se designaria de "grupos vulneráveis": crianças e gestantes. Embora os indicadores de infecção da doença estivessem baixando, a curva de notícias era crescente na lógica midiática.

Essa profusão de textos se apresentou a partir de distintos formatos: reportagens, notícias, notas, editoriais, cartas dos leitores e diversos outros. Pode-se dizer que, em vários deles, identifica-se uma dimensão biográfica, na qual a vida do indivíduo constituía-se um eixo narrativo através do qual a história da doença foi se construindo. As matérias abaixo referentes a diferentes momentos da doença ilustram com clareza este ponto:

Um telefonema da Fundação Oswaldo Cruz acabou ontem com a angústia vivida pelo casal Dayse Malheiros, 33 anos, e Fernando Malheiros, 33. Moradores de Volta Redonda, a médica e o advogado estavam de quarentena, impedidos de sair de casa desde a última segunda-feira. Foi quando Dayse, que tinha sintomas de gripe e havia passado a lua-de-mel em Cancun, no México, procurou um hospital e descobriu que poderia estar com a gripe suína. (02/05/09, "Fim da angústia em Volta Redonda", ESPECIAL DO DIA, p. 3)

Ela nasceu há 25 dias, aos 8 meses de gestação, com $33 \mathrm{~cm}$ e 2,4 $\mathrm{kg}$. Sofia Vitória começou a lutar pela vida ainda no ventre da mãe, Carla Lima de Oliveira Gomes, 23 anos, uma das nove gestantes que morreram no Estado do Rio com diagnóstico comprovado de gripe suína. (24/08/09, " A vitória de Sofia, a única órfã da gripe suína no Rio", RIO DE JANEIRO, p. 4)

Eles não se conhecem, mas suas histórias de vida - marcadas pela perda de pessoas queridas nas epidemias de dengue e da gripe suína - têm em comum o mau atendimento médico que culminou com a morte dos filhos, irmãs e mulheres. (30/08/09, “Mau atendimento contribuiu para mortes por gripe [suína] e dengue",p.8)

Cabe notar que a dimensão biográfica ilustrada por estes exemplos aparece dentro do texto informativo, tendo sido explicitamente trazida pelo autor da matéria (o jornalista), que a mesclou com outros dados. (Casadei, 2010). Percebe-se que ela foi obtida por meio da entrevista e muitas vezes vem 
expressa também pelo discurso direto, o qual traz a interioridade do sujeito, suas emoções, relato de ações e assim por diante ("Eu não aguentava mais a clausura. O resultado do exame descartando a doença tirou um peso de minhas costas", contou Dayse" (02/05/09, “Fim da angústia em Volta Redonda”, ESPECIAL DO DIA, p. 3)

Pode-se dizer que a dimensão biográfica é também encontrada em outros espaços do jornal O Dia, em especial nas sessões intituladas Viva Voz e Carta Aberta, que apresentam, juntos, um significativo número de textos: dez e dois, respectivamente. Trata-se de duas colunas de estrutura muito semelhante, cujos elementos se resumem a um pequeno texto com assinatura, uma suscinta qualificação do autor (sua profissão e idade ou ainda a relação daquela pessoa com a doença) e, por fim, uma frase em destaque:

\author{
VIVA VOZ \\ Gisele Gomes de Lima \\ Telefonista, 22 anos, gestante \\ "Só ouço falar que essa gripe mata. Tive muito medo" \\ "Há sete anos tenho desavenças com a minha sogra, mas dessa vez \\ selamos a paz. Foi ela quem tomou a iniciativa para ligar para o Tel- \\ essaúde, e eu tenho apenas que agradecer. Só ouço falar que essa \\ gripe mata grávida. Quando vi que estava com febre e falta de ar, tive \\ medo de morrer.
}

A ambulância chegou na minha casa em menos de meia hora. No hospital fui atendida imediatamente. Fizeram vários exames e descartaram o risco de gripe suína. Um alívio. Agora vou ficar de licença por sete dias, já que trabalho em uma sala fechada e há pessoas gripadas lá. Só quero me recuperar. (07/08/09, VIVA VOZ, p. 4)

Nestes casos, diferente do que foi mostrado anteriormente, o efeito que o texto provoca não é o de uma fala trazida pelo jornalista e organizada em meio a seu texto, mas parece ser a própria voz do outro, fora do texto informativo, materializando-se em um espaço autônomo (inclusive na diagramação do jornal) no qual aparece como autor, narrador e personagem, configurando o pacto autobiográfico, nos termos propostos por Lejeune.

Cabe ainda uma segunda observação sobre as narrativas autobiográficas analisadas nas sessões Viva Voz e Carta Aberta. Ao trazerem uma profusão de "relato[s] retrospectivo[s] em prosa sobre sua própria existência", não encontramosum relato completo, com início, meio efim, englobandoatotalidade 
da trajetória do indivíduo, mas sim fragmentos da vida ancorados na experiência da doença. Certamente isto está relacionado, entre outras coisas, aos modos de enunciação do discurso jornalístico, cujas regras normatizam o tamanho do texto, a abrangência do relato e se pautam pelos critérios de noticiabilidade. Encontramos assim pequenas histórias, que amenizam e humanizam o relato dos acontecimentos, trazendo detalhes pouco conhecidos, o que nos aproxima da noção de biografema - no caso, autobiografema, proposta por Leonor Arfuch (2010). ${ }^{2}$

A autobiografia - ou, no caso, o autobiografema - reflete, como foi dito anteriormente, a construção do self. No entanto, cabe lembrar o contexto de produção destes relatos. Independente se eles são obtidos via entrevista ou pela redação direta do autor/narrador/personagem, no caso da sessão Viva Voz, ou se são enviados por carta, na Carta Aberta, esses textos são enquadrados pelo jornal, que seleciona as fontes adequadas a seus propósitos, edita o texto, escolhe quando e onde vai publicar. Assim, podemos dizer que neles encontramos a construção de identidades (a vítima, os suspeitos de contaminação, o paciente etc.), as quais, a despeito de estarem ancoradas na ideia de indivíduo, estão narrando uma história coletiva que revela os modos pelos quais estão sendo construídos os sentidos sobre a doença no jornal.

\section{SENTIDOS E FORMAS DAS NARRATIVAS \\ AUTOBIOGRÁFICAS SOBRE INFLUENZA H1N1}

O primeiro texto analisado, datado de 01 de maio, traz "André Luis, jogador de futebol", que estava naquele momento no México, descrevendo o impacto da doença na sua rotina. Com o destaque para a frase "Antes do treino, nós precisamos limpar as mãos com álcool gel para entrar em campo", o jogador constrói sua fala a partir de seu lugar de pai. "Tenho 3 filhos pequenos que não saem de casa para nada", diz ele, e é a partir desta posição no mundo que ele fundamenta a sensação de medo e fragilidade diante da doença. Mas, acima de tudo, a persona que é construída neste "texto" é a da vítima em potencial, uma vez que está de fato situado no epicentro do contágio. Neste momento a identificação com o leitor é dada, na medida em que somos todos passíveis de contrair a doença que rapidamente se espalha pelo mundo.

2 O termo biografema também foi utilizado por Roland Barthes (1977) e, na sua acepção, diz respeito a uma situação discursiva na qual o texto fragmenta o sujeito a ponto da pulverização, fazendo com que o ancorado em pormenores detalhados, em fragmentos da vida. 
$\mathrm{O}$ relato da experiência pessoal do jogador frente à Influenza H1N1 no México traz uma dimensão testemunhal: estamos diante de um observador privilegiado dos acontecimentos, que presencia os eventos da doença no principal local em que ela ocorre neste momento (México). Seligmann-Silva assinala como a noção de testemunho está próxima da cena jurídica, na qual

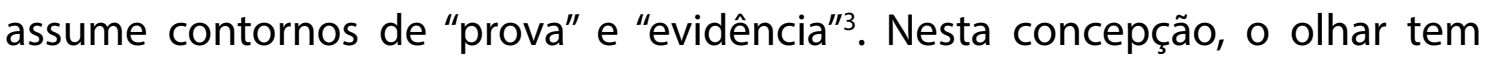
precedência, portanto, o testemunho é aquele que vê um acontecimento, sua presença é fonte de autoridade para comprovar a existência do ocorrido e relatá-lo para o mundo. Citando Walter Benjamin, o autor diz que o testemunho não tem apenas poder de "prova" mas também de "convencimento" (a um júri) - o que, no caso de um relato no jornal, assume um sentido especial frente aos leitores (Seligmann-Silva, 2005).

O segundo caso é o de "Dayse Malheiros, médica, 33 anos", publicado no dia seguinte. Trata-se de uma jovem que passou sua lua-de-mel em Cancun, México, e que ao voltar ao país manifestou sintomas da doença sendo obrigada a ficar de quarentena. Descrito pela frase "Nunca imaginei que pudesse passar por uma quarentena, sem sair de casa. Fiquei depressiva", o relato de Dayse novamente traz uma dimensão de interioridade, emocional, psicologizante. O breve trecho narra seu alívio com o resultado negativo, a preocupação com a cidade (caso estivesse infectada poderia se transformar em um vetor de contaminação), a angústia com a possibilidade de o marido estar contaminado e a "depressão" com a quarentena. Sua experiência frente à doença não é calcada na referencialidade externa, na observação de outros, dos objetos, do mundo, mas do "eu". O relato tem um tom confessional, de desabafo. Dayse encarna, em alguma medida, um personagem da narrativa midiática sobre a doença que representava um dos protagonistas neste momento: o "caso suspeito" e "monitorado".

O tom confessional é também encontrado na sessão Viva Voz dos dias 09 e 11/06/09. Na primeira há dois textos em uma mesma página e os autores são anônimos, descritos sob suas iniciais: "B., primeiro paciente isolado, 21 anos" e "D., segundo paciente isolado, 26 anos". Trata-se dos primeiros casos ocorridos no país, tanto o contraído fora como o da primeira contaminação autóctone. Ainda nesta mesma condição de "caso infectado", aparece no dia 11/06 "Rodrigo A, estudante, 22 anos". Em todos os exemplos, novamente o foco é nas emoções evidenciadas, e agora além do medo e da preocupação encontramos culpa:

3 Para tanto, o autor investiga o testemunho na literatura, partindo da cena grega, em especial da tragédia Agamêmnon, de Ésquilo, e trazendo também o testemunho da Shoah e o testimonio da ditadura na América Latina (SELIGMANN-SILVA, 2005). 
"Fiquei com peso na consciência de transmitir o vírus" (B.)/"A febre não passa e isso está me preocupando" (D.)/“Estou preocupado, já são dois casos na minha casa" (Rodrigo A.).

Embora em todos os casos (inclusive o de Dayse Malheiros) esteja presente o tom confessional, observa-se um claro deslocamento de emoções, motivado pela mudança de estatuto da vítima na narrativa sobre a Influenza H1N1 no jornal. Se antes o grande protagonista da narrativa sobre a doença era o "vírus", agora ele passa a ser aquele que contraiu a doença. Após sair da condição de "suspeito", período liminar no qual se situava numa condição intermediária (Turner, 1974), assume a nova identidade de "doente", na qual recebe diferentes nomes: "vítima", "paciente", "infectado", "portador do vírus" e "vetor". Esse sistema de nomeação revela os sentidos assumidos pela sua nova condição. Trata-se de um "paciente" que deve ser tratado pelo saber médico, uma "vítima", condição "usual" daqueles que são afetados por uma doença, mas neste caso uma vítima ambígua, pois carrega a dupla condição daquele que sofre mas também daquele que provoca o sofrimento. Afinal, está "infectado", é "portador" e "vetor" de transmissão. Deve ser protegido, mas também a sociedade deve dele se proteger. Assim se entende sua paradoxal condição de "celebridade anônima", pois todos conhecem o seu caso mas se protege a sua identidade para que não seja vítima de preconceito. Perde seu nome e sua individualidade, mas sua nominação pelas iniciais remete à ideia de criminalização.

Com o decorrer dos acontecimentos sobre a doença, passado o momento inicial de novidade e com a multiplicação dos casos, surgem como personagens novas modalidades de vítimas. Dois grupos foram identificados: os jovens e as gestantes. O primeiro aparece em um Viva Voz do dia 25/06/09 e nas duas únicas Cartas Abertas encontradas (27/06/09 e 02/07/09). Aqui, o debate sobre a doença já se concentra nas estratégias de prevenção, e a escola aparece como o grande local de perigo, que deve, portanto, ser "controlado". No primeiro Viva Voz temos o relato do pânico na escola: "Minha filha de 11 anos me ligou apavorada: ' todos estão com a mão na boca para não pegar". Aqui, a narradora Ana Lúcia Oliveira aparece em função dupla, a de representante da filha (a vítima em potencial) ao dar voz a ela e a de mãe zelosa. Relata seus sentimentos de "surpresa" e "apreensão" e sua conduta para que sua filha retornasse à sala com as amigas e aguardasse orientação da escola.

Este é, no entanto, o único que traz de forma explícita um certo descontrole sobre a doença. Os demais representam testemunhos de dois casos de jovens que contraíram a Influenza H1N1 e se recuperaram prontamente, um narrado pela própria paciente, outro pela mãe da jovem. Trata-se de narrativas de superação 
que retomam um tom testemunhal. No entanto, aqui ele não adquire tanto contornos jurídicos, de prova, mas de se aproxima do testemunho religioso, em que se vem a público para relatar uma experiência de transformação e cura. Essa transformação, no entanto, não se deu pela transcendência, mas pela "cidadania", e aqui vem revestida de uma fala prescritiva e moral. A mãe, ao relatar como a filha conseguiu superar a doença, enumera seus atos (providenciou máscaras, separou banheiros, lavou sempre as mãos). Nesta "prestação pública de contas", dá "lições" sobre como proceder, delineando o "certo" e o "errado". Diz a mãe em um certo momento: "(...) as pessoas tendem a fugir das suas responsabilidades" - ela não fugiu às suas, foi exemplar como cidadã e, acima de tudo, como mãe.

O segundo grupo de pacientes são as gestantes (ou textos sobre elas), cujos trechos aparecem todos em agosto (07, 16 e 24/08/09). Seus relatos são fortemente marcados pelo medo, onde é enfatizada a letalidade do vírus, como demonstram as frases em destaque: "Só ouço falar que essa gripe mata. Tive muito medo!" ("Gisele Gomes de Luma - telefonista, 22 anos, gestante"); "Temos medo. Estou grávida e tenho um filhinho" (Helen Marília Oliveira - estudante, 33 anos). Embora no enquadramento geral a última fala se aproxime um pouco da fala testemunhal de superação (como revela o título da matéria "A vitória de Sofia, a única órfã da gripe suína no Rio"), vemos a avó Kátia de Oliveira relatando a perplexidade com a morte da filha, que escapou de bala perdida, mas veio a morrer de algo tão aparentemente banal como uma gripe.

O último personagem que aparece no Viva Voz trazendo sua experiência pessoal é "André Marques, ator e apresentador". Neste caso, observa-se que os elementos de sua vida estão menos presentes. Embora minimize os efeitos da gripe ("Estou aqui parado, mas me sentindo ótimo, sem febre"), e seja também bastante econômico na menção a fatos de sua vida privada, ele no entanto é bastante fluente nos detalhes sobre o que entende ser uma postura confusa das autoridades sanitárias na condução da doença. O que está em jogo é uma fala acusatória; o apresentador usa a sua experiência como arma, respaldado na sua condição de "famoso", para denunciar o que ele entende como sendo a incompetência do poder público.

Por fim, cabe ressaltar uma exceção. Encontramos um relato sobre a doença no Viva Voz que não trouxe, de forma alguma, a dimensão da experiência ou do biográfico. Trata-se do caso de "Luci Vicente de Faria", sacristã-mor da Igreja de são Jorge". "A freqüência não mudou. Nossos fiéis são fervorosos". Dentro do texto ela diz: "Na hora da consagração da hóstia, eles (os padres) passa álcool gel nas mãos" 
Em comum nessas histórias é que revelam narrativas extremamente emocionais e que evocam permanentemente laços familiares. São pequenos dramas familiares, nos quais acompanhamos pais, casais, irmãos, avós, noras e sogras construindo-se publicamente como bons familiares e bons cidadãos. Em todos esses casos a categoria "experiência" tem fundamental importância. É o vivido que confere estatuto de legitimidade a essas narrativas, seja para testemunhar, desabafar, acusar ou outra ação discursiva.

Embora a presença da experiência seja de certa forma constitutiva da autobiografia, há ainda uma outra dimensão que se quer destacar. Ao ressaltarmos a sua presença neste espaço específico, do jornalismo, isso permite repensar o dito benjaminiano de que trata-se de uma arte em extinção (Benjamin, 1996). Mais viva do que nunca, ainda que reinventada, encontramos narradores que recorrentemente passam uma vivência acoplando no relato uma dimensão moral e acima de tudo utilitária, com sugestões práticas, trazendo formas de "se portar" em sociedade. Culpa, indignação, alívio, medo, acompanhados em diversos momentos de conselhos, servem para explicar e prescrever como se prevenir, o que fazer (e não fazer) caso adoeçam.

No entanto, cabe ressaltar que, diferente do que retrata Benjamin, não se trata de uma moral "aberta", que evita dar "explicações" e permite a dimensão mágica. Ainda que, no limite, todo processo de recepção traga uma dimensão polissêmica, na qual o leitor é simultaneamente um coprodutor de sentidos, o que se quer enfatizar é que, do ponto de vista da história narrada, há uma proposta mais fechada. Trata-se de uma moral prescritiva, que implica em uma pedagogia do cuidado de si e do outro com sentidos muito precisos. Outra distinção importante a se trazer é que não se trata de uma comunicação oral, face a face, mas de um narrador que chega ao "ouvinte"/leitor mediado pelo jornal, o que instaura uma vivência coletiva de outra natureza, trazendo suas marcas a esses relatos de experiência.

\section{CONSIDERAÇÕES FINAIS}

O autobiográfico apareceu no jornal O Dia através de pequenas narrativas ("autobiografemas"), que se expressam a partir de subgêneros tais como testemunho, desabafo, confissão, acusação, sempre articulando uma gramática das emoções (preocupação, medo, alívio, culpa, vergonha, indignição) a uma gramática da moralidade (o bom familiar, o bom profissional, o bom cidadão). Ao mesmo tempo em que esses relatos se estruturam a partir da ideia de indivíduo, fundado na interioridade e na experiência pessoal da doença, eles estão simultaneamente vinculados a uma dimensão exterior, ligada à narrativa 
sobre a doença. Ou seja, o que está sendo narrado não são especificamente as históricas pessoas, mas a partir dos relatos individuais se dramatiza um acontecimento social, no caso, o episódio da Influenza H1N1 no estado do Rio de Janeiro.

Nesse sentido, entendemos que a importância das narrativas biográficas na construção da subjetividade contemporânea tem impactado o jornalismo de modo a constituir, com a produção de espaços autobiográficos, um novo "pacto de referencialidade", que não é só calcado na "realidade exterior", mas na pessoal. Nesse sentido, percebemos uma mudança na enunciação jornalística, ampliando a presença do "outro", de suas narrativas de vida, no destaque dado ao discurso direto.

No caso de Viva Voz, temos uma nova configuração para o discurso direto. $\mathrm{Na}$ ocasião da pandemia de Influenza H1N1, o discurso direto saiu da trama narrativa e assumiu uma relativa autonomia, tanto espacial quanto autoral: espacial, na medida em que ganhou um destaque fora da reportagem, como um box próprio; e autoral, por fazer com que o personagem passe a assumir a função de autor. Como argumentamos, essa autonomia é relativa, porque o Viva Voz estava inserido num determinado contexto narrativo, produzindo um complementaridade dos sentidos propostos pela reportagem.

Desse modo, o Viva Voz e Carta Aberta operava como um modo de produzir a evidência pela experiência. Dessa forma, a verdade é dada pelo estatuto da evidência e tem, assim, a aparência de inquestionável: não se poderia questionar o que se está vendo, o que está sendo relatado como vivido. O Viva Voz, portanto, tomou a evidência como verdade, uma aparente ausência de mediação, como se o real chegasse ao leitor sem mediação, imediatamente. Nesse ponto, cabe, ainda, diferenciar o Viva Voz da Carta Aberta. O Viva Voz é um alargamento do discurso direto. Já a Carta Aberta também conta com uma dimensão demonstrativa, assim como uma relação de complementaridade e interdependência com o texto principal. É por isso que entendemos o porquê de tais textos não estarem publicação na seção de "Carta de Leitores". Na Carta Aberta, por sua vez, a autoria é mais evidente do que no Viva Voz.

Nas páginas de ODia, Viva Voz e Carta Aberta ganharam não só destaque, mas uma relativa autonomia do corpo da reportagem. Isso acontece, porque o espaço para o outro foi destacado. Nessa configuração, o status de autor passou a ser atribuído também ao personagem. $O$ alargamento da autoria permite que o discruso direto aparece como uma autobiografema. No entanto, isso não implicou uma perda da autoridade jornalística, mas, ao contrário, novas formas de legitimação desta prática e deste ator, o jornalista. É como se a experiência 
estivesse saindo da realidade para ir diretamente ao leitor, produzindo um apagamento da mediação jornalística e construindo um espaço de publicação de um fragmento da vida do outro com as palavras próprias.

Nesse sentido, o uso da autobiografia no jornal inverte a lógica usual do jornalismo, redesenhando tanto as fronteiras das concepções modernas do público e do privado e do exterior e do interior. O jornalismo de O Dia, no caso, passou a contar com uma outra ordem de referencialidade - a autobiográfica, subjetiva, tida como sincera e verídica também nas páginas do jornal. É interessante notar também que, no momento de recrudescimento da referência ao "eu" do jornal - a autorreferenciação -, também se dê um aumento dos relatos biográficos nos jornais.

Concluímos, portanto, que o modo de endereçamento de O Dia a um público intermediário (entre as classes médias e populares) fez com que o jornal usasse a narrativa individual para se aproximar do leitor. Foram personagens/ autores do Viva Voz e da Carta Aberta o jogador de futebeol, o apresentador de TV, a avô zelosa, a médica de classe média que passou a lua de mel em Cancun, entre outros. Nessa estratégia de identificação, observamos que houve um reforço da autoridade jornalística, por tornar o real mais imediato, mais próximo da identificação pessoal: aquele que sofre com a doença se assemelha e é facilmente identificado pelos leitores do jornal.

\section{REFERÊNCIAS}

ARFUCH, Leonor. $O$ espaço biográfico: dilemas da subjetividade contemporânea. Rio de Janeiro: Ed. UERJ, 2010.

BENJAMIN, Walter. O narrador. Considerações sobre a obra de Nicolai Leskov. In: Magia e técnica, arte e política: ensaios sobre literatura e história da cultura. São Paulo: Editora Brasiliense, 1996.

CASADEI, Eliza Bachega. A construção de personagens no jornalismo: entre a matriz de verdade presumida e a imaginação das urdiduras de enredos. In: Ciberlegenda, Rio de Janeiro, v. 1, n. 22, p. 77-91, mar. 2010.

COELI, Humberto de Lemos Medina. O novo jornalismo popular: a reforma do jornal O DIA e suas consequências. 2003. 152 f. Dissertação (Mestrado em Comunicação) - Faculdade de Comunicação, UnB, Brasília, 2003. 
DUMONT, Louis. O individualismo. Rio de Janeiro: Ed. Rocco, 1985.

Homo Hierarchicus: o sistema de castas e suas implicações. São Paulo: EDUSP, 1992.

FAUSTO NETO, Antônio. Mortes em derrapagem: os casos Corona e Cazuza no discurso da comunicação de massa. Rio de Janeiro: Rio Fundo, 1992.

LEJEUNE, Philippe. O pacto autobiográfico. Belo Horizonte: Ed. UFMG, 2008.

MAUSS, Marcel. Uma categoria do espírito humano: a noção de pessoa, a noção de eu" In: _. Sociologia e Antropologia. São Paulo: Editora Pedagógica e Universitária (E.P.U.), 1974.

SELIGMANN-SILVA, M. Testemunho e a política da memória: o tempo depois das catástrofes. In: Projeto História, São Paulo, v.1, n.30, p. 71-98, jun. 2005.

TURNER, Victor. O Processo ritual: estrutura e antiestrutura. Petrópolis: Editora Vozes Ltda, 1974.

VELHO, Gilberto. Memória, identidade e projeto. In: Projeto e metamorfose. Rio de Janeiro, Jorge Zahar Editor, 1994.

Recebido em: $15 / 12 / 2014$

Aceito em: 20/1/2015

Endereço dos autores:

Igor Sacramento <igorsacramento@gmail.com >

Fundação Oswaldo Cruz, Instituto de Comunicação e Informação Científica e Tecnológica em Saúde.

Avenida Brasil, 4036 / Sala 504

Manguinhos - CEP 21040361 - Rio de Janeiro, RJ - Brasil

Telefone: (21) 38829250

Kátia Lerner < klerner@icict.fiocruz.br>

Fundação Oswaldo Cruz, laboratorio de Pesquisa em Comunicacao e Saude.

Av Brasil 4036 sala 516

Manguinhos - CEP 21040-361 - Rio de Janeiro, RJ - Brasil

Telefone: (021) 38829146 